\title{
Should patients be allowed to look after their own medical records?
}

\author{
Raanan Gillon Imperial College, St Mary's Hospital Medical School and King's College, London University
}

'There are no substantial practical drawbacks and considerable ethical benefits to be derived from giving patients custody of their medical records' argue Mary Gilhooly and Sarah McGhee in this issue of the journal (1). Since, with the exception of maternity records, such custody is rare their arguments require careful consideration. In particular how do they meet the objections to patient-held records offered by many practising clinicians; objections which presumably account for the rarity of such arrangements?

The first potential objection they confront is a legal one - that patients have no legal right to see their notes let alone to have possession of them. The authors point out that the recent Access to Health Records Act modifies this fact in that under its provisions patients $d o$ have limited access to their notes in so far as their doctors do not believe that such access will cause them substantial harm, and in so far as the privacy of others can be respected despite such access. The important point here however is that absence or restriction of patients' legal rights of access in no way precludes doctors from giving them access. (And of course if there are good reasons to grant such access, then even if the law did preclude such access - which it does not - there would be good grounds to work to change the law).

The next objection considered is that if patients were allowed to look after their notes they would lose them. To counter this they cite one empirical study showing that patients in a major London teaching hospital in fact lost their notes considerably less than did hospital staff (!); and two other studies showing that patients were very unlikely to lose their own or their children's notes.

A third objection considered is that patients would require more time with the doctor to discuss the contents of their medical records, at least because they would wish to have some of the contents explained. Empirical studies cited tend to support this claim, though one indicated an average requirement of only ten additional seconds of consultation time per patient when records were discussed; in another the authors felt the additional time spent was justified by the benefits obtained. This certainly supports the prima facie case that if patients want to discuss aspects of their case that they do not understand such discussion is desirable and likely to be beneficial - and one way of finding out what the patient would like explained is to give him or her access to the case record.

The authors meet the argument that it would be too costly to reduplicate and update patient-held records by (implicitly) two types of counterargument. One accepts the charge and suggests that duplication would not be needed - patients would simply have custody of their notes instead of hospitals or general practices. If that were done, write the authors, there would be a net saving in time and money, 'storage of records in general practice surgeries and hospitals would cease to be problematic' and 'the savings in salaries for medical records staff could perhaps be used to hire more nurses'. Alternatively, if two sets of records were regarded as desirable, and accepting that duplication of the whole record would be excessively costly, the authors argue that shortened versions, and in particular credit card sized 'smart cards' with embedded computer chips, largely overcome the problem of cost. And to be set against the undoubtedly substantial cost of even the most economical smart card technology the authors offer several compensating benefits: locums and deputies making home visits would have access to the patient's records; new doctors would have access to their new patients' notes on first meeting them, even if the main case notes had not yet been forwarded from the previous doctor; and above all, argue the authors, patients would be able to correct inaccuracies in their own records - and they cite several empirical studies showing that a significant percentage of medical records contain inaccuracies.

Against the argument that doctors would feel restricted in what they might write in the notes the authors argue 'and a good thing too' if it means they don't write down such offensive 'surgical witticisms' as GRT (Guardian reading teacher), NLM (nice looking mum) and FLK (funny looking kid). There can be little doubt that possibly amusing but almost certainly potentially offensive and gratuitous remarks have no place in a professional record. The point of a clinician's medical records is surely first and foremost to promote the health of the patient and any remark that fails to support that objective is prima facie irrelevant; if in addition it would be found offensive by the patient it is almost certainly better omitted. Some comments however may be written as part of the objective of 
promoting health and still be found offensive by the patient. The authors give the example of 'suspected child abuse'. Here perhaps it is worth adding a consideration; not only is the content of the note of relevance, so too is the way it is presented. Would 'nonaccidental injury?' be less offensive than 'suspected child abuse' to a parent reading a young child's note (it is a further question of course at what age/stage of development a child's notes should be made unavailable to the parents)? Would 'weight in top one percentile' or some other non-judgemental equivalent be less offensive than 'grossly obese'? It seems clear that a policy of open access to notes should bring with it a review of medical terms and terminology likely to be found offensive by patients; terms such as 'hysterical', 'neurotic', 'senile', 'geriatric', are among those that doctors would do well to revise, given their pejorative, even abusive, connotations.

It is perhaps with psychiatric diagnoses and notes that the most difficult problems arise if patients have access to and custody of their notes. Despite frequent special pleading that psychiatric record-keeping is qualitatively different from other types of medical record-keeping, with its increased reliance on subjective interpretation and even personal value judgement by various members of the treatment team, the authors reject as 'ethically difficult' a discrimination against psychiatric patients in the context of access to and custody of their notes; they suggest that the need to invoke the 'therapeutic exception' 'probably reflects a deterioration in the psychiatrist-patient relationship'. But they acknowledge that this area is particularly problematic. Perhaps one relevant issue in this context is whether or not the psychiatric disorder is sufficiently severe to impair severely the autonomy of the patient; with patients whose autonomy is severely impaired by whatever cause, but including severe psychiatric illness, there seems good justification to withhold psychiatric notes where access is believed to be harmful to the patient. Where, however, severe impairment of autonomy is not involved (and of course many patients with psychiatric problems are nonetheless adequately autonomous or competent to make their own decisions) then on the whole is it not potentially positively useful for such patients to have access to their notes and use them as a basis for further discussion/psychotherapy? Arguments and empirical evidence to that effect are presented by Dr David Healy (2); among them is the efficiency of such an approach - he told a Society for Applied Philosophy conference in May this year that by giving psychiatric patients access to their notes, and by inviting them to comment on them, alter what they disagreed with and engage in dialogue about them with the doctors, such patients are recruited as health care workers in their own cause: at a time when shortage of resources and staff is a critical issue such a prospect should appeal on grounds of additional resources alone!

Is access to notes, and thus their custody, likely to cause patients distress? The authors cite a variety of empirical studies indicating the contrary. Nonetheless there can be no doubt, even on the basis of the empirical evidence cited that some patients will be $\stackrel{0}{\rightarrow}$ made anxious and upset by items they read in their $\bar{C}$ notes, and certainly in our own general practice, where patients have had open access to their notes for many years, there have been occasional examples of marked distress. But it has been possible to remedy matters, in correct and apologise for mistakes (including changing a hospital letter from 'diabetes and syphilis' to ? 'diabetes insipidus'!): and to reassure a patient that a $\vec{\omega}$ differential diagnosis of ' $\mathrm{Ca}$ ' indicated only a possibility to be ruled out, rather than a diagnosis made. A small minority of patients are likely to be distressed if they read their notes and it is unwise to assume otherwise. But no one has to read his or her notes, and distress is usually a price worth paying for those who choose to do so. Furthermore the empirical evidence cited by the authors shows that, overall, access to records reduces patients' distress.

The authors also cite empirical studies that counter 'the prevalent view' that patients do not want access to their notes and would be unwilling to look after their own records - from 80 to 96 per cent of patients appreciated access to their notes and from 55 to 71 per cent liked looking after their records. Nor do the empirical studies cited by the authors support claims that access to notes harms rapport between patien and their doctors - on the contrary.

Finally, the authors consider the issues of confidentiality. Clearly, so far as the patient is concerned if he or she wishes to see the record it is absurd to invoke the doctor's duty of confidentiality to prevent this - for the doctor's duty of confidentiality stems from respect for the patient's own wishes. There is, however, a problem of confidentiality not addressed by the authors, notably respect for the confidentiality of letters in the notes sent by other health care workers: a consultant psychiatrist, for example, may have sent a letter 'in strict confidence', perhaps to a previous general practitioner; in such cases surely the confidentiality of the sender has to be taken into account when assessing whether or not to leave such letters in the notes. The problem would of course diminish if it became the norm for doctors to give their patients access to their notes (and indeed our own practice notepaper is headed with the statement 'in this practice patients have open access to their notes') so that consultants may take this fact into account.

On the whole, clinicians worried about the potential problems of patients having access to and custody of their notes should be reassured by this paper.

\section{References}

(1) Gilhooly M L M, McGhee S M. Medical records: practicalities and principles of patient possession. Fournal of medical ethics $1991 ; 17$ : 138-143.

(2) Healy D. The suspended revolution - psychiatry and psychotherapy re-examined. London: Faber, 1990. 